\title{
As boas intenções e os maus resultados
}

\author{
Luiz Francisco Rebello
}

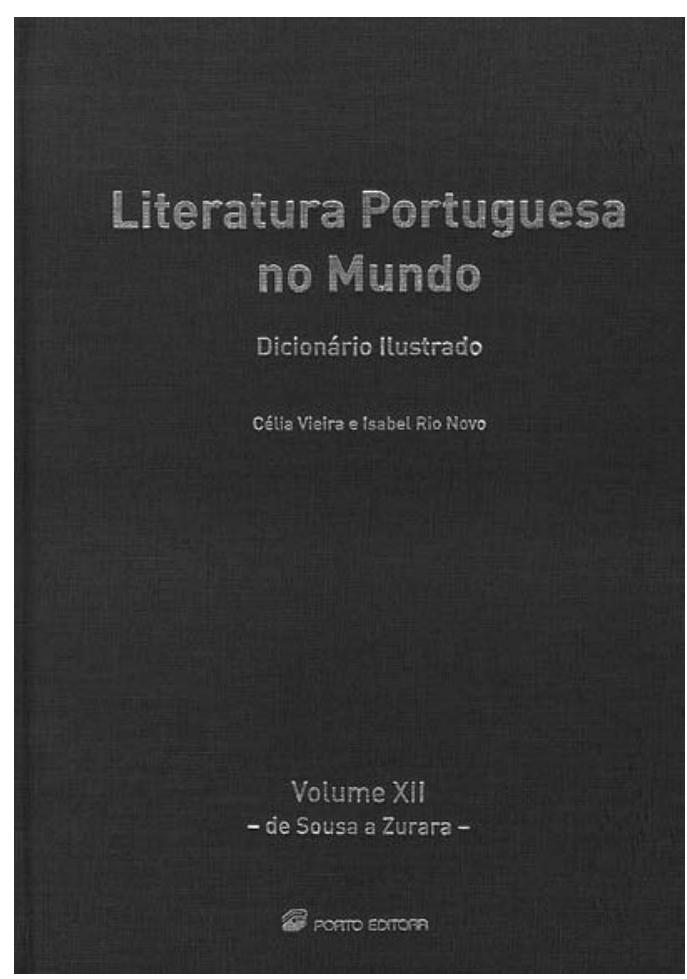

Um dicionário de literatura não pode, obviamente, ignorar a literatura dramática - digo literatura dramática, não o teatro, que é realidade diversa, de que aquela é apenas (mas não se veja nessa ressalva qualquer conotação pejorativa) um dos elementos estruturantes. Acontece, porém, que por via de regra o espaço que lhe é concedido em obras deste tipo prima pela escassez, circunscrevendose aos grandes nomes de autores (sobretudo se comuns a outras áreas) e aos títulos das obras principais, como se só destas e daqueles uma dramaturgia se compussesse.

A esta lamentável regra faz excepção o dicionário das professoras Célia Vieira e Isabel Rio Novo, em que a literatura teatral está amplamente representada, tanto no que toca a autores como a obras. Compare-se, por exemplo, o lugar que Ihes é aqui outorgado com o que ocupam nos dicionários, a outros títulos modelares, de Jacinto Prado Coelho ou Álvaro Manuel Machado: é notória a distância que os separa. Sob este aspecto quantitativo, só há que louvar as intenções das autoras de A literatura portuguesa no mundo. Mas ai se detém o nosso aplauso.

Porque não é a esse nivel que o trabalho claudica, e sim ao da nomenclatura, da estrutura formal e da microestrutura. Há lacunas e omissões graves em matéria de autores e obras; e mesmo em relação aos (e às) que foram dicionarizados (/as) são muito discutiveis os critérios

\author{
Célia Vieira e lsabel Rio Novo, Literatura \\ portuguesa no mundo (dicionário ilustrado), \\ 12 vols., Porto, Porto Editora, 2005.
}

da respectiva hierarquização e insuficiente, quando não indigente e até por vezes errada, a informação prestada ao leitor. Ao longo do dicionário, que se reparte por 12 volumes com mais de 100 páginas cada um, tão numerosos são os exemplos que ilustram o que acabamos de afirmar, que teremos de limitar-nos aos mais flagrantes.

Neste tipo de obras que preenchem uma função didáctica, os critérios objectivos terão de prevalecer sobre a subjectividade dos gostos; estes só podem (só devem) manifestar-se no terceiro daqueles niveis, mediante a emissão de juizos identitários e valorativos da produção literária considerada. Em qualquer dos casos, um mínimo de rigor é sempre exigível. Não responde a essa exigência este dicionário.

Porque há-de começar-se por algum lado, seja pelas omissões de autores e obras, reservando para depois o inventário, que não será exaustivo, dos erros e inexactidões em que é pródigo. Assim, não pode deixar de estranharse a ausência de entradas relativas ao Padre Luis da Cruz (séc. XVI), Nicolau Luis, João Baptista Gomes e António Xavier de Azevedo (séc. XVIII), César de Lacerda, Fernando Caldeira, Ernesto da Silva (séc. XIX), André Brun, Coelho de Carvalho, Augusto de Castro, Vasco Mendonça Alves, Fernando Amado (séc. XX), tão dignos de figurar - pelo menos - quanto outros contemporâneos seus que não foram esquecidos. Estranho é também que não se depare qualquer referência à presença, que está longe de ser despicienda, do teatro na obra de autores como José Agostinho de Macedo, Camilo, Gervásio Lobato, Mário de Sá-Carneiro, Aquilino Ribeiro, Torga, David-Mourão Ferreira. E daria pano para muitas mangas uma análise comparativa do espaço dedicado aos autores compendiados: cotejemse, por exemplo, as entradas relativas a José Freire de Serpa Pimentel, figura menor da dramaturgia romântica, e de outro lado Eduardo Schwalbach ou Augusto Sobral.

Mas a extensão do desastre é mais vasta no que respeita às obras. Logicamente, Gil Vicente é o autor a cuja obra corresponde o maior número de entradas: como explicar, porém, que entre elas não figure o auto da Visitação, que inaugurou a literatura dramática entre nós, nem o auto da Alma, que marca o apogeu dos seus autos "de devação"? E que estejam ausentes os Enfatriões de Camões, 0 cerco de Diu de Simão Machado, 0 fidalgo aprendiz de Francisco Manuel de Melo, Assembleia ou partida de Correia Garção, qualquer dos Morgado(s) de Fafe de Camilo, Meia noite de D. João da Câmara, A Severa de Júlio Dantas, Belkiss de Eugénio de Castro, Sabina Freire 
de Teixeira Gomes, Continuação da comédia de João Pedro de Andrade, Jacob e o anjo de José Régio, A promessa ou o Pecado de João Agonia de Santareno, Os degraus de Augusto Sobral (que nem sequer é mencionado no artigo sobre o autor), Um jeep em segunda mão de Fernando Dacosta? Ou que, na obra de Alfredo Cortez se haja escolhido, com exclusão de qualquer outra, uma peça, 0 oiro, que, e cito Carlos Porto, "não é representativa nem sequer do teatro do seu autor", deixando de fora Zilda, O lodo, Tá-mar, e sobretudo Gladiadores, peça fundamental da nossa dramaturgia contemporânea? E que de fora ficassem também a Dulcineia de Carlos Selvagem e O render dos heróis de Cardoso Pires, obras sem dúvida bem mais importantes e mais significativas que $A$ encruzilhada daquele ou Corpo-delito na sala dos espelhos deste, com que estão aqui representados? Tudo isto já seria grave. Mais grave ainda é a total omissão - digo bem: total - de entradas relativas às obras dramáticas de Marcelino Mesquita, Lopes de Mendonça, Raul Brandão, António Patrício, Almada Negreiros, Fiama Hasse Pais Brandão e Saramago. Como é possivel que num dicionário que visa apresentar "a literatura portuguesa no mundo" não figurem Dor suprema e Peraltas e Sécias, 0 azebre, 0 doido e a morte e 0 Gebo e a sombra, 0 fim e D. João e a máscara, Deseja-se mulher, Quem move as árvores, A noite?

... Mas, em contrapartida, houve lugar para bagatelas como A indiana de Tomás Ribeiro, Um divórcio de António Enes, A Senhora da Paz de Cipriano Jardim, e até para a "comédia heróica" de Alfredo Hogan 0 dia $1^{\circ}$ de Dezembro de 1640 que, pormenor interessante, não chegou a ser representada no Teatro do Ginásio "por causa da morte inesperada do jovem rei D. Pedro V"! (Abra-se aqui um parêntesis para lamentar que as autoras não se tivessem lembrado de referir também que peças como Felizmente há luar e 0 judeu não puderam representar-se, ou foram retiradas de cena como 0 motim, por imposição da censura). $E$, tornando ao que iamos dizendo, registe-se a enormidade de ser Mendes Leal, justiceiramente acusado por Teófilo Braga de haver "corrompido e tornado estéril a obra de Garrett", o dramaturgo com maior número de entradas próprias depois de Gil Vicente: nada menos que oito, entre as quais se incluem duas (Pobreza envergonhada e Os homens de mármore) que são, confessadamente, imitadas de (ou inspiradas em) peças do repertório francês! A Serpa Pimentel, Hogan e Enes couberam três entradas, mas Natália Correia e Santareno tiveram de contentar-se com duas, e outros, como Jorge de Sena, José Régio, D. João da Câmara, nem tanto.

Mais não seria necessário acrescentar, se não houvesse ainda que abordar a longa e penosa teoria de inexactidões factuais, imprecisões e contradições, de que o dicionário está recheado. 0 que segue é apenas uma amostra. Começaremos, cronologicamente também, por Gil Vicente, de quem se diz que "se serviu pela primeira vez da língua portuguesa" na farsa Quem em farelos? de 1515, quando já o fizera cinco anos antes no auto da Índia. Um suposto Auto terceiro atribuido ao Chiado não é senão a mesma Prática dos compadres também citada, como se lê no frontispício da edição quinhentista. 0 teatro clássico foi "introduzido" ou "inaugurado" em Portugal ora por António Ferreira (p. 32 do volume V), ora por Sá de Miranda (p. 28 do volume VIII): é óbvio que só o segundo termo da alternativa é correcto, como a leitura dos respectivos artigos evidencia. 0 título original da comédia Bristo de António Ferreira, tal como figura na edição príncipe de 1562, é Comédia do fanchono, o que aqui se omite. Simão Machado, que se diz pertencer à "Escola vicentina" (designação imprópria que a crítica actual proscreve) na entrada respectiva, é mais adiante referido como tendo "rompido com o teatro vicentino". A obra completa do árcade Manuel de Figueiredo consta de 16 volumes, e não de 13 , como se informa na respectiva entrada. Ernesto Biester não "introduziu em Portugal o drama de actualidade com Os operários" (1865), pois que o Pedro de Mendes Leal o antecedeu pelo menos em oito anos. Nem A viagem à roda da parvónia de Guerra Junqueiro e Guilherme de Azevedo é uma "comédia satírica" nem Constança é um "poema dramático" de Eugénio de Castro, mas sim, respectivamente, uma revista ("relatório" Ihe chamaram os autores) e um poema lírico em 7 cantos. Os reinegros 
que na p. 91 do volume XII se inclui entre as peças de teatro de Alves Redol, com a data de 1966, é quatro páginas adiante um romance póstumo editado em 1972 - e esta segunda informação é que está certa. Norberto Ávila não traduziu nenhuma peça de Jan Kott, que aliás nenhuma escreveu, mas sim o célebre ensaio Shakespeare, nosso contemporâneo; por outro lado, o seu drama Os deserdados da pátria, dado como inédito, foi publicado em 2003. Como em 2002 se publicou a peça de Borges Coelho Sobre os rios de Babilónia, pelo que 0 príncipe perfeito não é "o seu único texto dramático". A adaptação teatral da Relíquia, atribuída exclusivamente a Luis Sttau Monteiro, foi escrita em colaboração com Artur Ramos. Ao contrário do que se afirma, A birra do morto de Vicente Sanches foi várias vezes levada à cena e transmitida pela RTP. Alguém terá de morrer e É urgente o amor datam de 1956 e 1958, e não de 1982 e 1970 . Etc., etc.

Não se julgue, porém que só o teatro foi vítima de tantos e tais maus tratos. A ficcção novelesca, a poesia, o ensaio e a crítica tão-pouco escaparam. Três exemplos bastarão. Seja o primeiro a classificação do romance de José Régio 0 príncipe com orelhas de burro como "história infantil" (já Benilde ou a Virgem-mãe fora acoimada de "drama realista"). 0 segundo, o esquecimento de autores da importância de Manuel Teixeira-Gomes (não obstante haver entradas relativas a duas obras suas, Gente singular e Inventário de Junho), Carlos Malheiro-Dias, José-Augusto França, Frederico Lourenço, Eugénio Lisboa, Eduardo Pitta, Guilherme de Melo, Jacinto Prado Coelho, Bernardo de Passos; e de obras tão relevantes como A farsa e Os pobres de Raul Brandão, Nome de guerra de Almada Negreiros, A toca do lobo de Tomás de Figueiredo, As sombras de Pascoaes (de quem aliás nenhuma obra tem direito a entrada específica). 0 terceiro exemplo, bem demonstrativo da leviandade (é o mínimo que pode dizer-se) com que o livro foi elaborado, respeita ao filósofo Uriel da Costa, cujas datas de nascimento e morte se não indicam mas se sabe serem 1583 ou 84 a primeira e a segunda 1640, ano em que se suicidou após ter concluido esse extraordinário documento que é Exemplar humanae vitae, publicado em 1687, que erradamente se dá a entender como sendo o ano da sua escrita. E as duas obras que se Ihe atribuem, o Tratado da imortalidade da alma e o Exame das tradições farisaicas, não estão perdidas (data de 1995 a mais recente edição de ambas), com a agravante de só a segunda ser de Uriel Costa. A primeira deve-se a Samuel da Silva, e é uma refutação das teses heréticas de Uriel, que precisamente sustentava ser mortal a alma do homem, como reitera no tratado em que responde àquele seu "contraditor". Sem dúvida, errare humanum est, como reza a locução latina; e quem esta crítica assina por certo algumas vezes terá errado. Mas acrescenta a locução que perseverare diabolicum. Até para o erro há limites.

Uma palavra ainda para a descuidada revisão (há remissões sem correspondência no texto, como Náufragos de Fernanda de Castro, e muitas entradas para as quais não se faz qualquer remissão) e para as incriveis opções da iconografia. Já não se compreende que nenhum texto relativo a obras teatrais seja ilustrado por uma fotografia de cena, um cartaz, uma maqueta; nem que muitos o sejam por fotografias de cidades em que os autores visados nasceram ou episodicamente viveram. Mas ilustrar as entradas sobre António Quadros, Guiomar Torresão e José Duro por retratos de Albert Camus, François Coppée e Baudelaire porque os dois primeiros os traduziram e 0 terceiro foi influenciado pelo autor das Fleurs du mal; a Avenida de Roma de Artur Portela por uma fotografia da rua Augusta; a Távola redonda por um retrato de Pablo Neruda, cuja poética é precisamente o emblema daquela "literatura, empenhada e social" contra a qual é dito a revista insurgir-se; ou o artigo sobre António Pedro por um quadro de Kandinsky..., toca as raias do absurdo. E porquê privilegiar a reprodução de capas de edições recentes, muitas vezes do pior gosto, e só raramente recorrer às edições principes?

Fiquemos por aqui. Estará o inferno cheio de boas intenções. Mas que lugar reservar então para os maus resultados? 